\title{
Rubrics for academic dissertation assessment. Does peer assessment work?
}

\author{
Cristina Pardo García ${ }^{a}$, Vicent Caballer Tarazona ${ }^{b}$, María Caballer Tarazona ${ }^{a}$ \\ ${ }^{\mathrm{a}}$ Department of applied economics (Universitat de València, Spain), ${ }^{\mathrm{b}}$ Department of economics and \\ Social Sciences (Universitat de Politècnica de València, Spain)
}

\begin{abstract}
In the recent context of student-centered learning, they are more involved in the whole learning process, while the teacher is only a guide through their learning. This implies that students must be also involved in the assessment process. Following this idea, the peer assessment tries to give the students the opportunity to be in the evaluator position and maybe experience a reflexion about the criteria, what an external person sees in what he/she has to assess.
\end{abstract}

When students have the role of assessing their classmates work, they pay more attention to the content and formal details of the presentation; therefore they can easily identify key points involved in an academic dissertation. This is a good opportunity to actively learn some basic transversal skills for any kind of presentation.

Under this context, we present in this paper a comparison of the marks given by both students and teachers, to the same academic dissertation. In addition, we provide the rubric provided to students as a guide for the assessment.

As results show, the students' final decision to assess their peers' work is quite close to the teacher's decision. Only light differences were identified, on average, students gave a slightly higher mark to their classmates than the teacher did. However, a correlation on students and teacher marks was found.

Keywords: peer assessment, autonomous learning, group activities 


\section{Introduction}

One of the objectives of the peer assessment is to make students reflect on their own performance. Since they are evaluating their classmates, they can be more aware of which aspects are key to be understood by the class, how to transmit the message to get effective communication.

Some aspects highlighted in the oral presentation lesson were:

- Follow a logical outline in the presentation: objective, introduction, methodology, results and conclusions.

- Slides should be well designed: the text size should be readable, an appropriate balance between text and figures is needed and an attractive design.

- The presentation should fit in the allowed time.

- The important information should be delivered, dividing the allowed time among the different parts of the talk (introduction, methodology, results, conclusions).

- Take into account the audience, the message should be adapted to it.

- The language should be formal, avoiding colloquial expressions and with a vocabulary adapted to the audience.

- A good presenter has to show his/her passion about the topic, he/she has to inspire the audience, make it interesting.

- All these aspects were assessed with the peer assessment evaluation form. In fact, the transversal competences worked in the subject include the use of ICT technologies and communication in an effective way.

There can be also a difference between the teacher assessment and the peers assessment, since the teacher evaluates the written work and the presentation, while the students only the presentation. In fact, apart from having a similar performance in both tasks (written work and presentation) other extreme and opposite cases can occur as well:

- A very well written work with a presentation that is not so good.

- A poor written work with a presentation that is acceptable.

These situations can conditionate the different perception of the teacher and the students.

\section{Related literature}

Peer assessment helps with knowledge construction, promotes discussion and cooperative learning (Lee, 2017). First year students are the younger ones in university, but they are supposed to be able to assess their classmates. However, it is true that students must have 
assessment professionalism to provide their peers with meaningful and constructive feedback (Lee, 2017).

Tenorio et al. (2016) did a systematic literature review on peer assessment in on-line learning environments. They found that $60 \%$ of the articles showed peer assessment improvement in student performance, $33 \%$ of articles reported some advantages for teachers, some studies presented peer assessment difficulties related to student motivation, which can spoil the peer review process. In fact, other tools can be used to create quizzes or questionnaires for students (Kahoot, Moodle, Sporcle...) (Caballer-Tarazona, 2018).

Obviously, developing a critical attitude is also another transversal competence that is trained with this activity of peer assessment. Peer evaluation makes students think more critically about their own performance, put themselves in the place of the other, such as the teacher, the person who will evaluate them (Filgueira Arias and Gherab Martin, 2016).

Nevertheless, evaluating others is not an easy task, and students should be provided with some indicators in which to focus on and also the scale that must be applied. When organizing a peer assessed activity, it is advisable to give them previously a rubric or some grading criteria to help them to do this evaluation better (Lopez-Pastor et al., 2016).

The position of evaluator comparing teacher and students can present differences. Usually the peer assessment task is applied to an activity which the students have to do as well as authors or active agents. This maybe gives the students a different point of view than the one of the teacher, who only guides the work but does not make one himself/herself. However, Martínez-Sala et al (2015) did a peer review experience and found that the students marks given by their peers were very similar to the marks given by the teacher, with no representative differences. Students reported a positive opinion about the peer review assessment method.

Sometimes students can complain that their peers' marks are not fair. In fact, peer assessment offers the students the opportunity to approach to subjectivity in marking, maybe bringing closer the positions of tutors and students in evaluation processes (McConlogue, 2012). In fact, empathy is enhanced when one is placed in the position of other agent.

One common criticism to peer rating in group environments is that it is likely to be biased, with the resulting unfair marks. This bias seems to happen because of the friendship relationships and social interactions that go unavoidably with group task activities. The term reciprocation entails the tendency for two people who are asked to rate each other to be influenced in their evaluation task by social relations between them. These reciprocity effects are apparently a source of bias (Magin, 2001). 
They are other peer assessment that can be implemented which is the peer evaluation between members of the same team. In our activity, they only evaluate other teams performance as a whole, not individuals. When they know their mark in the team project is conditioned by the performance of their group mates, maybe they are more critical.

\section{Activity}

This methodology was applied within the combined degree of Tourism and Business Administration from the University of Valencia. During the first year of this degree students take a compulsory introductory subject aimed to acquire some transversal skills, such as academic writing, structure of an academic report, oral presentation and so on. Within this context, at the beginning of the term, students choose by teams a type of tourism and during all the term, with the guide of the teacher they elaborate a report and a powerpoint presentation in teamwork. At the end of the term, each group delivers the writing report to the class and the teacher and performs a presentation in the practical class.

Some students were worried about having to present their work through an oral presentation. It was in a reduced context, that means, it was not delivered to the whole group, which was formed by 58 students. The objective was to do the presentation in the practical classes, which were 3 groups of 20 students each approximately. Besides, the environment is also different. While a presentation to the whole group would be in a big classroom with an upper part for the teacher, the practical classrooms are smaller, all the floor is at the same level, and it yields to a more familiar and close environment.

Another difficulty they found was to fit their presentation to the time given. Students do not see the time as another condition to perform the task. The content should be split and some time should be devoted to the presentation, outline, introduction, main content, results and conclusions. Some of them took too much time for introduction purposes and they ran out of time during the results, with no time for conclusions.

However, we have to keep in mind that they are first year students, and they will practice oral presentations in other subjects. Therefore, learning process is a progressive improvement. They will learn from this first presentations skills and tips that will be followed in future similar activities.

At the end of each presentation, the classmates have to fill in the rubric provided by the teacher for evaluating the work of their classmates. 


\section{Methodology}

The teacher provides a short rubric to students as a guide to evaluate their classmates presentation. The teachers in the subject did not want that the rubric was too long, since we were interested in they paying attention to the presentation. For each of the five items included in this rubric, students should give an score from 1 to 10 presented as a Likert scale, where 1 is very poor and 10 is excellent (see Table 1). Each student has to evaluate other 4-5 group presentations of the classmates in the same practical class.

The evaluation form was created in Google Forms, so students just enter the link provided in the virtual classroom and evaluate their classmates choosing in the Likert scale provided. They can use their smartphones, tablets or computers in the classroom to fill in the form. A specified time was given after each presentation for the students to do that, around 3-5 minutes.

Table 1. Rubric for students to give a grade (1-10).

\begin{tabular}{|l|l|}
\hline Aspect considered & Grade \\
\hline $\begin{array}{l}\text { Are the slides properly designed? (readability, balance between text and figures, } \\
\text { attractive design, etc.) }\end{array}$ & \\
\hline Has the group demonstrated confidence and good oral expression? & \\
\hline Has the presentation adjusted to the established time? & $\begin{array}{l}\text { The group has dealt with the most important aspects of the subject. The precise } \\
\text { information has been provided to understand it. It's clear for me? If someone asks } \\
\text { me, will I be able to explain it to someone else? }\end{array}$ \\
\hline $\begin{array}{l}\text { My knowledge about the subject has increased significantly and I found the } \\
\text { presentation entertaining and interesting }\end{array}$ & \\
\hline
\end{tabular}

Peer reviews collected were 172. The distribution depended on number of teams in each practical class and the number of people in each group (3-4 mostly, exceptionally 5 people). Responses varied for teams in Practice 1 having 10 peer reviews each while teams in Practice 2 and Practice 3 having 13 peer reviews each. 


\section{Results}

Here we present the comparison between the average marks given by students and the teacher's mark in the team project. These detailed marks for each team can be seen in Table 2 .

Table 2: Average marks given by students and teacher mark for each team.

\begin{tabular}{|c|c|c|}
\hline Team & Students mark (on average) & Teacher mark \\
\hline 1 & 7,36 & 8,00 \\
\hline 2 & 6,63 & 6,00 \\
\hline 3 & 7,07 & 7,00 \\
\hline 4 & 8,74 & 8,00 \\
\hline 5 & 7,53 & 6,00 \\
\hline 6 & 7,27 & 7,50 \\
\hline 7 & 7,99 & 7,50 \\
\hline 8 & 7,90 & 6,00 \\
\hline 9 & 8,42 & 7,20 \\
\hline 10 & 8,45 & 8,30 \\
\hline 11 & 7,38 & 6,10 \\
\hline 12 & 7,23 & 5,20 \\
\hline 13 & 7,98 & 8,00 \\
\hline 14 & 7,89 & 7,00 \\
\hline
\end{tabular}

The teacher's mark was higher than the students mark only in 3 team projects of the 14 teams considered. Specifically, that happened in teams 1, 6 and 13 (see Figure 1). 


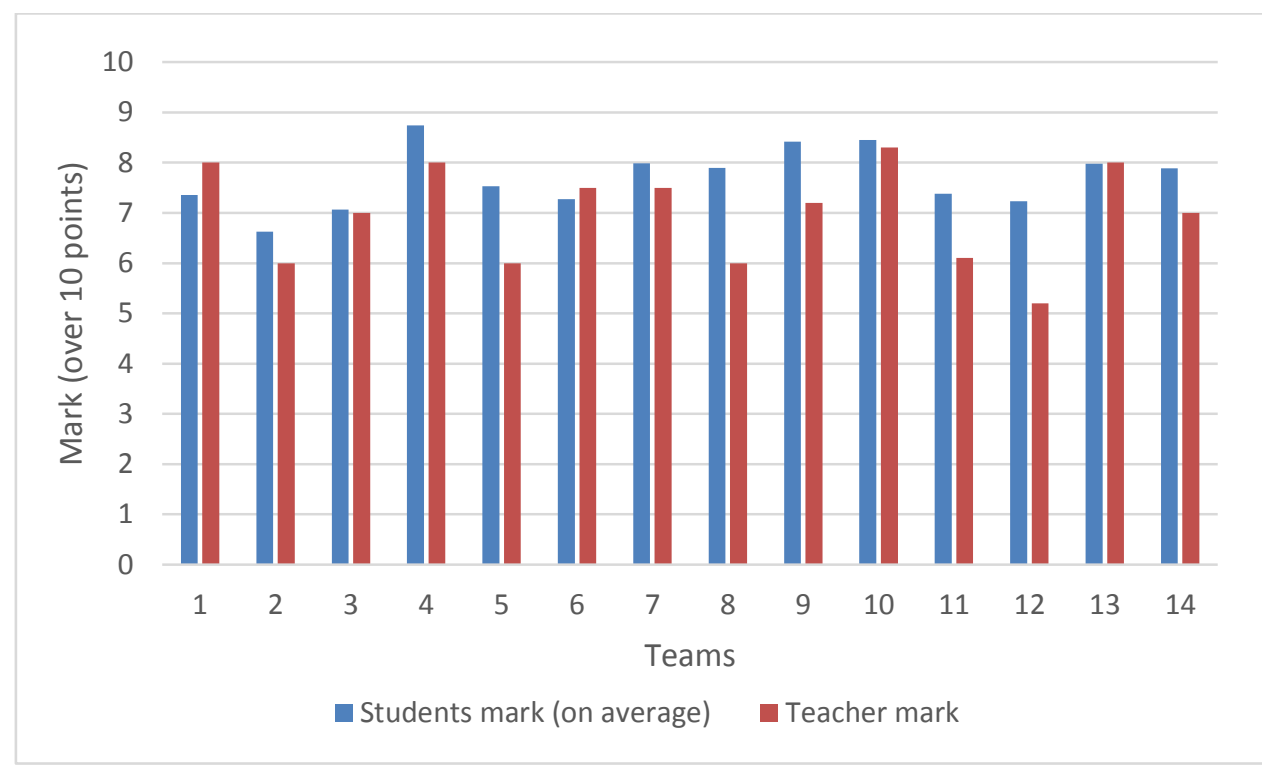

Fig. 1: Team marks given by the students (peer assessment) and the teacher.

After comparing marks given by students and teacher for each team, we are going to get the global mean for both, see Table 3 . Computing the average marks

Table 3: Descriptive statistics of marks given by students and teachers.

\begin{tabular}{|l|l|l|l|}
\hline & Mean & Standard deviation & Coefficient of Variation \\
\hline Students'mark & 7.70253 & 0.593409 & $7.7 \%$ \\
\hline Teacher's mark & 6.98571 & 0.971800 & $13.91 \%$ \\
\hline
\end{tabular}

$\mathrm{n}=14$

As shows Table 4 on average students give a higher mark than teacher, but with a smaller standard deviation. The coefficient of variation shows that in fact, the teachers mark presents a higher relative dispersion. Therefore, we can say that the mark of the teacher discriminates more between good and bad works. Students maybe show a central tendency to consider their classmates work as acceptable.

We can also analyze the linear relationship between students mark and teacher mark. For that, we compute the correlation coefficient between both variables, see Table 4 . 
Table 4: Correlation between Students' mark and teacher's mark.

\begin{tabular}{|l|l|r|r|}
\hline \multicolumn{4}{|c|}{ Correlations } \\
\hline \multirow{4}{*}{ Students mark } & Pearson Correlation & Students mark & Teacher mark \\
\cline { 2 - 4 } & Sig. (bilateral) & 1 &, $558^{*}$ \\
\cline { 2 - 4 } & $\mathrm{N}$ & &, 038 \\
\hline Teacher mark & Pearson Correlation &, $558^{*}$ & 14 \\
\cline { 2 - 4 } & Sig. (bilateral) &, 038 & 14 \\
\cline { 2 - 4 } & N & 14 & 14 \\
\hline *Correlation is significative at 0.05 level (bilateral). \\
\hline
\end{tabular}

However, Table 4, shows a positive and significant correlation but not too high, between the mark given the teacher and those given by students. Therefore, the higher the mark given by students, the higher the mark given by the teacher. That mean that peer-evaluation could be a good approximation to the teacher assessment.

As was said, the correlation is significant but not too high, maybe due to the fact that the student assessment was based only on the presentation while the teacher assessment was based both on the presentation and written report. This fact could also explain the difference on standard deviation of the mark; the teacher has more elements to discriminate between good and bad works.

The students can be driven by empathy in their peer assessment, that is, if they do not want to receive a bad mark in the presentation, they tend to give mainly good marks in order to not harm their classmates and maybe because they expect a kind of reciprocity in return.

\section{Conclusions}

Within the line of the Bologna process, we try to involve students in the whole learning process by organizing activities which allow students' participation. In this paper we propose to involve students in their peer assessment process through the use of rubrics provided as guide by the teacher. We think that place students in the evaluator position is a 
good way to easily identify common errors and learn from their classmates. In some cases, explanation between peers are more effective than a teacher speech. In addition, the exchange of roles (from assessed to evaluator) is an efficient teaching strategy. In this case, students can learn by doing, first by elaborating their project and presentation and second, by focusing on the improvables point of their peers.

Further than the pedagogical goal of this activity, our results show as marks given by students are in the majority of the cases quite close to the teacher marks. Specifically, we obtain that on average students give a mark of 7,7 while the average mark given by the teacher is 6,9 . Even if the average mark given by students is higher than that given by the teacher, the mark standard deviation is higher for the teacher, that could mean that the teacher is more capable to discriminate the quality of the works.

As a general conclusion we would like to remark that this activity was useful to increase the attention of students in their peer presentations, and in addition, it contributed to the learning process.

\section{References}

Caballer Tarazona, Vicent (2018) Online quiz design through Sporcle [Diseño de cuestionarios online mediante Sporcle], IV Jornadas sobre Sistemas de Votación Electrónica 2018.

Filgueira Arias, C. and Gherab Martin, K. (2016) Learning through collaborative work and peer assessment, Expressivamente, 1, 42-54.

Lee, C. (2017) Assigning the appropriate works for review on networked peer assessment, Eurasia Journal of Mathematics Science and Technology Education, 13 (7), 3283 3300. Retrieved from: https://doi.org/10.12973/eurasia.2017.00717a

Lopez-Pastor, V. M.; Perez-Pueyo, A.; Barba, Jose and Lorente-Catalan, E. (2016)

Students' perceptions of a graduated scale used for self-assessment and peerassessment of written work in pre-service physical education teacher education (PETE), Cultura, ciencia y deporte, 11 (31), 37-50. http://www.redalyc.org/pdf/1630/163044427005.pdf

Martínez-Sala, R.; Molina-Mateo, J.; Tort-Ausina, I. and Meseguer-Dueñas, J. M. (2015) Peer review based evaluation in team work: students' assessment, Proceedings of the 8th International Conference of Education, Research and Innovation (ICERI), 980985.

McConlogue, T. (2012) But is it fair? Developing students' understanding of grading complex written work through peer assessment, Assessment \& Evaluation in Higher Education, 37 (1), 113-123. https://doi.org/10.1080/02602938.2010.515010 
Magin, D. (2001) Reciprocity as a source of bias in multiple peer assessment of group work, Studies in Higher Education, 26 (1), 53-63.

https://doi.org/10.1080/03075070020030715

Tenorio, T.; Bittencourt, I. I.; Isotani, S.; Silva, A. P. (2016) Does peer assessment in online learning environments work? A systematic review of the literature, Computers in Human Behavior, 64, 94-107. 